\title{
Metastatic uterine leiomyosarcoma in association with recurrent lung abscess
}

\author{
NICK SHERON, MERYL GRIFFITHS, NORMAN MCI JOHNSON \\ From the Department of Respiratory Medicine, Middlesex Hospital, London
}

\begin{abstract}
A case of metastatic uterine leiomyosarcoma complicated by recurrent lung abscesses is described.

Nearly all smooth muscle neoplasms of the uterus are benign, but in some instances apparently innocuous tumours metastasise to the lungs. ${ }^{1-4}$ We report a patient with a 21 year history of low grade uterine leiomyosarcoma of the uterus and pulmonary secondary deposits complicated by recurrent lung abscesses.
\end{abstract}

\section{Methods}

A 57 year old woman presented in December 1987 with a

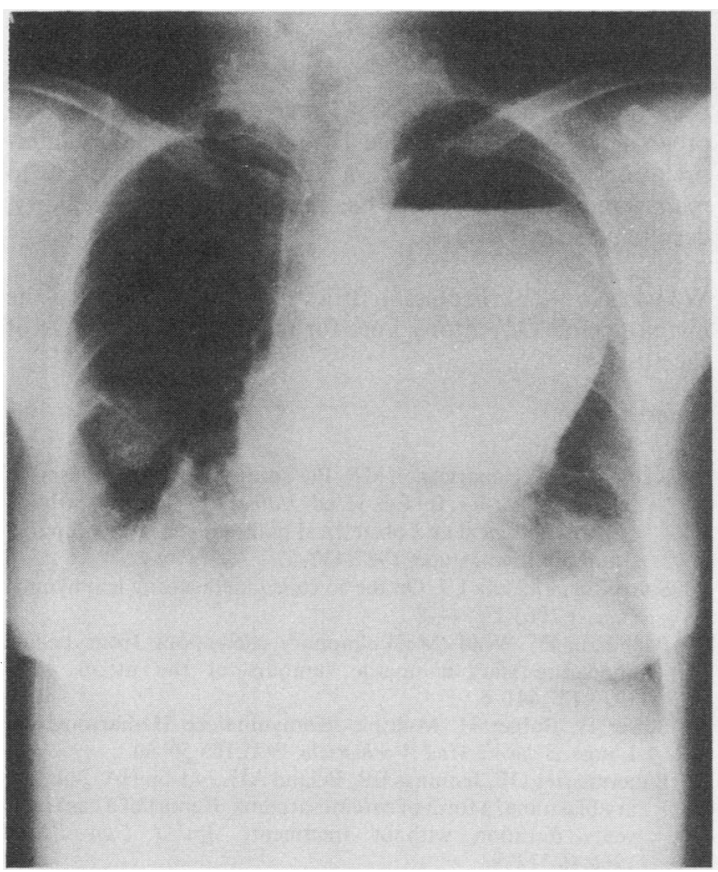

Fig 1 Chest radiograph on admission in 1987 showing the large left upper zone abscess and rounded tumour mass in the right lung.

Address for reprint requests: Dr Nick Sheron, 26 Colney Hatch Lane, London N10 IDU.

Accepted 5 April 1989 three week history of malaise, fever, and left sided pleuritic pain. Chest radiography showed a left upper zone abscess $14 \times 11 \mathrm{~cm}$ and several smaller rounded opacities in both lung fields (fig 1). Treatment with ampicillin and metronidazole was started, and a self retaining catheter was inserted percutaneously into the abscess under ultrasound control. About $900 \mathrm{ml}$ of sterile pus was drained, after which she immediately felt better and her temperature resolved. The drain was kept on continuous suction via a Roberts pump for 10 days, but was removed when a communication developed between the abscess cavity and a bronchus. Antibiotics were continued for one month and, although a small fluid collection has recurred, she remains well.

The patient had first presented in 1967, aged 35, with an ovarian cyst. At laparotomy a benign cyst had been resected and also the uterus, which contained several fibroids up to $13 \mathrm{~cm}$ in diameter. Histologically the fibroids were considered to be benign. The following year several rounded opacities were noted in the right lung on a routine radiograph, and subsequently the right middle lobe and most of the right lower lobe were removed. The resected specimen contained five well demarcated nodules of tumour ranging from eight to $30 \mathrm{~mm}$ in diameter. Histological examination showed interlacing bundles of spindle cells in which were scattered acini lined by columnar and cuboidal cells. A diagnosis of multiple pulmonary blastoma was made. Eighteen months later more nodules had developed in the left lung, and a decision was made against any further treatment.

By 1973 the nodules had increased only slightly in size, but multiple lung cysts were now present. In 1976 a left upper lobe abscess was drained and antibiotics were administered for four weeks. Although a small amount of fluid reaccumulated in the abscess cavity, she was well for six years. In 1982 two further left upper lobe abscesses were treated similarly. In 1984 a small collection of fluid was present in the cavity and over the preceding six years two of the pulmonary lesions had enlarged from 13 and $15 \mathrm{~mm}$ to 21 and $32 \mathrm{~mm}$.

We reviewed the histological specimens from the hysterectomy and the lung resection. The large uterine "fibroid," of which there were three histological sections available, would now be classified as "tumour of uncertain malignant potential." The mitotic rate of fewer than two mitoses per 10 high power fields was in the benign range but there was some atypical mitotic activity and nuclear pleomorphism, features now known to be associated with less predictable behaviour. The pulmonary tumours were histologically similar apart from the presence of epithelial lined acini (fig 2) communicating with pulmonary air spaces, which were undoubtedly pulmonary epithelial inclusions. The mitotic rate of 0.2 per 10 high power fields was lower than in the uterine tumour, but the appearances were those of a low grade metastatic uterine leiomyosarcoma. 


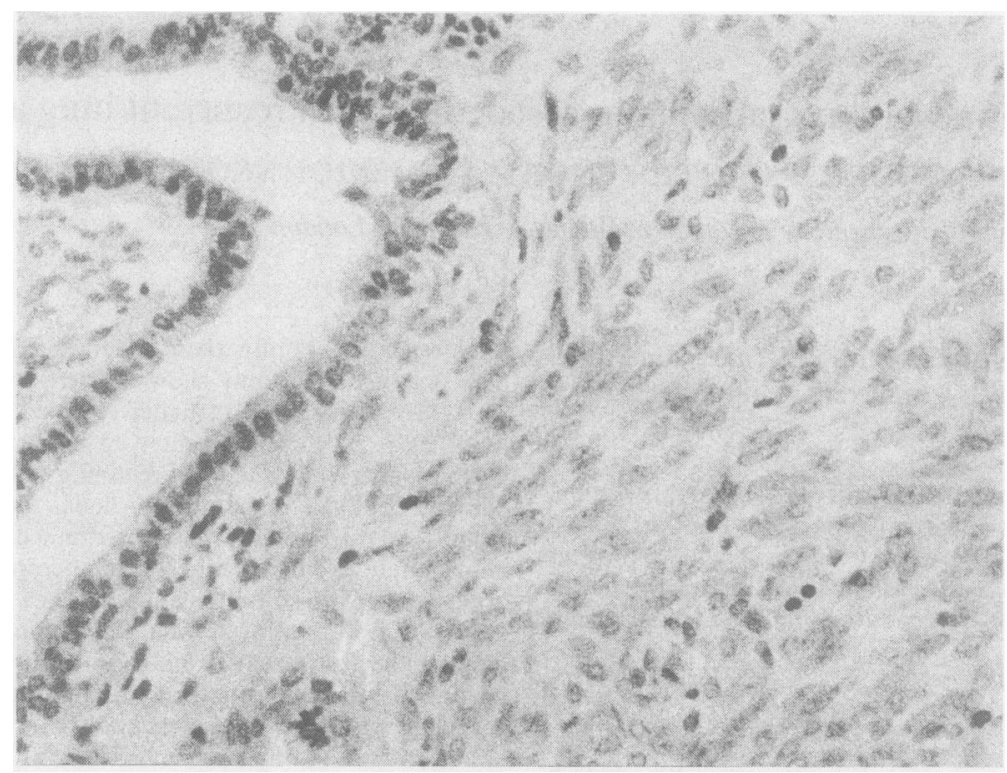

Fig 2 Histological appearance of one of the pulmonary tumours showing a uniform population of smooth muscle cells. The space is lined by incorporated pulmonary epithelium. (Haematoxin and eosin.)

\section{Discussion}

Although smooth muscle tumours of the uterus are extremely common, leiomyosarcoma is rare. Its prognosis is variable and correlates to some extent with the histological appearance. The presence of more than 10 mitoses per high power field is associated with a high risk of metastasis and a

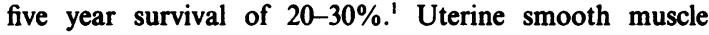
tumours with fewer than two mitoses per high power field are usually considered benign, but almost 30 cases of metastatic disease developing from apparently benign lesions have been reported. ${ }^{2}$ The importance of nuclear pleomorphism and atypical mitotic activity as additional prognostic indicators has recently been recognised in this group. ' Multiple primary pulmonary leiomyomas and fibroleiomyomatous hamartomas are probably also metastases from low grade leiomyosarcomas. ${ }^{3}$ Some patients have survived for up to 36 years with slowly progressive disease. ${ }^{4}$

This patient was originally misdiagnosed as having multiple pulmonary blastomas. Blastomas are rare tumours usually characterised by a primitive histological appearance with both mesenchymal and epithelial malignant elements. The prognosis is usually poor but prolonged survival in the presence of persistent disease has been reported. ${ }^{5}$ The confusion probably arose from the incorporation of epithelial elements within the tumour, a now recognised feature of metastatic leiomyosarcoma. ${ }^{6}$ Lung cysts have been associated with primary and metastatic leiomyosarcoma ${ }^{67}$ but no cases of lung abscess have been reported, which is perhaps surprising in view of the continuity observed between pulmonary air spaces and the epithelial lined spaces within the tumour.

Various approaches have been taken to the treatment of metastatic leiomyosarcoma. Small trials and isolated cases showing the benefit of chemotherapy and radiotherapy have been reported and spontaneous regression has occurred in pregnancy, ${ }^{8}$ but the variable natural history makes inter $\Omega$ pretation difficult.' So far, a conservative approach to $\overrightarrow{\overline{6}}$ management in this patient has resulted in little morbidity 3 despite persistent disease.

We wish to thank Professor Brian Corrin for reviewing the histology and Dr Antony Lees for imaging and drainage of the abscess.

\section{References}

1 Kempson RL, Hendrickson MR. Pure mesenchymal neoplasms of the uterine corpus. In: Fox H, ed. Haines and Taylor: Textbook of gynaecological and obstetrical pathology. 3rd ed. London Churchill Livingstone, 1987:430-5.

2 Spiro RH, McPeak CJ. On the so called metastasing leiomyoma.D Cancer 1965;19:544-8.

3 Bachman D, Wolff M. Pulmonary metastases from benign appearing smooth muscle tumours of the uterus. $A J R_{\mathscr{S}}$ 1976;127:441-6.

4 Sulser $\mathrm{H}$, Buhler $\mathrm{H}$. Multiple leiomyomatose Hamartome de $\mathrm{O}$ Lunge. Schweiz Med Wochenschr 1975;105:56-60.

5 Bauermeister DE, Jennings ER, Beland AH, Judson HA. Pulmon $\omega$ ary blastoma, a form of carcinosarcoma. Report of a case of 24 years duration without treatment. Am J Clin Pathos 1966;46:323-9.

6 Wolff M, Gordon K, Silva F. Pulmonary metastases with admixed epithelial elements from smooth muscle neoplasms. Am J Surg Pathol 1979:3:325-42.

7 Lillo Gil R, Albrechtsson U, Jacobson B. Pulmonary leiomyosar coma appearing as a cyst. Report of one case and review of the literature. Thorac Cardiovasc Surg 1985;33:250-2.

8 Horstman JP, Pietra GG, Harman JA, Cole NG, Grinspan S? Spontaneous regression of pulmonary leiomyomas during pregnancy. Cancer 1977;39:314-21.

9 Hannigan EV. Long term survival with metastatic uterine saro coma. NY State J Med 1985;85:195. 